\title{
Originals
}

\section{HLA-DR 3 is associated with a more slowly progressive form of Type 1 (insulin-dependent) diabetes}

\author{
J. Ludvigsson ${ }^{1}$, U. Samuelsson ${ }^{1}$, C. Beauforts ${ }^{2}$, I. Deschamps ${ }^{3}$, H. Dorchy ${ }^{5}$, A. Drash ${ }^{8}$, R. Francois ${ }^{4}$, G. Herz ${ }^{6}$, M. New \\ and E. Schober ${ }^{9}$ \\ ${ }^{1}$ Department of Pediatrics, University Hospital, Linköping, Sweden; 2 Sophia Children's Hospital, Rotterdam, The Netherlands; \\ ${ }^{3}$ Department of Pediatrics, Hôpital Hérold, Paris, and ${ }^{4}$ Department of Pediatrics, Hôpital Herriot, Lyon, France; \\ ${ }^{5}$ Department of Pediatrics, Saint Pierre University Hospital, Brussels, Belgium; ${ }^{6}$ Department of Pediatrics, Basel, Switzerland; \\ ${ }^{7}$ New York Hospital, New York, and ${ }^{8}$ Children's Hospital, Pittsburgh, USA; ${ }^{9}$ University Kinderklinik, Vienna, Austria
}

\begin{abstract}
Summary. The presence of HLA-DR 3 was analysed in 745 patients with Type 1 (insulin-dependent) diabetes with age at diagnosis between $1-19$ years. HLA-DR 3 and/or 4 was found in $678 / 745(91 \%)$ of the patients. Presence of DR 2 with neither DR 3 nor 4 was demonstrated in 15 patients. Patients with HLA-DR 3 without DR 4 presented with Type 1 diabetes more evenly over the year; they also presented without incidence peaks at 7 years or $10-11$ years, as seen especially in DR 3/4 patients. The DR 3 patients more often had mild disease with less ketonuria at diagnosis, less often ketoacidotic
\end{abstract}

symptoms and more often a subsequent partial remission. The apparently more severe disease among diabetic girls may, at least to some extent, be explained by their higher prevalence of HLA-DR 4. The differences found were similar in North America and Europe. The results suggest that Type 1 diabetes is a genetically heterogenous disease and that HLA-typing may be a useful marker of this heterogeneity.

Key words: Type 1 diabetes, children, HLA-types, heterogeneity, symptoms at onset, partial remission, genetic susceptibility.
The onset and progress of Type 1 (insulin-dependent) diabetes mellitus is variable. Some patients develop disease early in life with a very short duration of symptoms, and others become insulin-dependent after years of abnormal glucose tolerance or after years of what has been called Type 2 (non-insulin-dependent) diabetes mellitus. In a few patients infections or toxic agents have provoked or triggered the disease; in others the disease appears some time after certain infections $[1,2]$. In most patients, however, no single exogenous factor can be identified as the cause. Autoimmune phenomena seem to be involved in the development of Type 1 diabetes [3]. Some studies have indicated that HLADR 3, in particular, is connected to autoimmune reactions $[4,5]$. In an earlier study [6] we found differences regarding early manifestations of Type 1 diabetes between patients with HLA-DR 3 or HLA-DR 4 which supported the hypothesis that Type 1 diabetes may have a heterogeneous background. Patients with HLA-DR 3 had a tendency towards a milder onset of Type 1 diabetes than those with HLA-DR 4. The aim of this study was to confirm, on a larger patient group, that there is an association between disease progress and certain HLA antigens and to analyse whether this could in part explain differences associated with sex, age or season of diagnosis of Type 1 diabetes.

\section{Subjects and methods}

A questionnaire was mailed to those members of the International Study Group of Diabetes in Children and Adolescents (ISGD) who agreed to participate in the study (Table 1). Answers were returned regarding 745 HLA-DR-typed diabetic children, $389(52 \%)$ boys and $356(48 \%)$ girls, from the different countries (Table 2).

Their age at onset varied between 1-19 years, with a distribution as shown in Figure 1. Thus, in the age group 0-4 years, boys were overrepresented $(p<0.02)$. This distribution was very similar in the different participating centres.

\section{Statistical analysis}

The $\chi^{2}$-test was used for statistical evaluation. In the case of several comparisons, the $p$ value was corrected by multiplying $p$ by the number of comparisons.

Table 1. Questions included in a questionnaire to all members of the ISGD

\footnotetext{
Year and month of diagnosis (1st insulin injection)

Duration of clinical symptoms before diagnosis

Blood glucose at onset

Level of consciousness at diagnosis (clear, impaired or coma)

Ketonuria at onset (none, $+/++$ or +++ )

Partial clinical remission (insulin dose $<0.5 \mathrm{IU} / \mathrm{kg} 24 \mathrm{~h}$ and no

glucosuria/normal $\mathrm{HbA}_{1} \mathrm{C}$ )
} 
Table 2. Answers from 9 clinics regarding 745 HLA-DR-typed diabetic patients

\begin{tabular}{lrrr}
\hline \multirow{2}{*}{ Clinic } & \multicolumn{2}{c}{ DR-typed patients } & Total \\
\cline { 2 - 3 } & Boys & Girls & \\
\hline Hôpital Hérold, Paris & 80 & 74 & 154 \\
Herriot, Lyon & 7 & 6 & 13 \\
Saint Pierre Univ, Brussels & 47 & 35 & 82 \\
Kinderarzt F. H. M., Basel & 8 & 8 & 16 \\
Univ Kinderklinik, Vienna & 79 & 55 & 134 \\
Univ Hospital, Linköping & 68 & 64 & 132 \\
Childrens Hospital, Pittsburgh & 90 & 99 & 189 \\
New York Hospital, New York & 3 & 4 & 7 \\
Sophia Childrens Hosp, Rotterdam & 9 & 9 & 18 \\
\hline & 391 & 354 & 745 \\
\hline
\end{tabular}

Table 3. Distribution of HLA-DR-types among 745 diabetic children and adolescents

\begin{tabular}{|c|c|c|c|c|c|c|}
\hline & \multicolumn{2}{|c|}{ Boys } & \multicolumn{2}{|c|}{ Gitls } & \multicolumn{2}{|c|}{ Total } \\
\hline & $n$ & $\%$ & $n$ & $\%$ & $n$ & $\%$ \\
\hline $3 / 3,3 / 0,3 /-$ & 35 & 9 & 27 & 8 & 62 & (8) \\
\hline $3 / \operatorname{non} 2,3,4$ & 60 & 15 & 45 & 13 & 105 & (14) \\
\hline $3 / 2$ & 13 & 3 & 3 & 1 & 16 & (2) \\
\hline $3 / 4$ & 133 & 34 & 111 & 31 & 244 & (33) \\
\hline $4 / 4,4 / 0,4-$ & 35 & 9 & 37 & 10 & 72 & (10) \\
\hline $4 / \operatorname{non} 2,3,4$ & 75 & 19 & 88 & 25 & 163 & (22) \\
\hline $4 / 2$ & 8 & 2 & 8 & 2 & 16 & (2) \\
\hline $2 /$ non 3,4 & 4 & 1 & 11 & 3 & 15 & (2) \\
\hline \multirow[t]{2}{*}{ Others } & 28 & 7 & 24 & 7 & 52 & (7) \\
\hline & 391 & 99 & 354 & 100 & 745 & $(100)$ \\
\hline
\end{tabular}



Fig. 1. Boys tend to get Type 1 diabetes more often than girls at ages $0-4$ years $(p<0.02)$. $\square=$ girls; $\square=$ boys

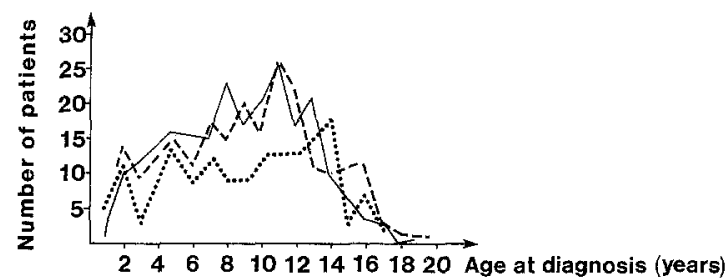

Fig. 2. Age at diagnosis in relation to HLA-DR $3 \ldots \ldots$; DR $4 \ldots$; DR $3 / 4-; n=626$

Table 4. Distribution of HLA-DR-types in the different countries

\begin{tabular}{|c|c|c|c|c|c|c|c|c|c|c|c|c|c|c|c|c|c|c|c|c|c|}
\hline & \multicolumn{3}{|c|}{ Austria } & \multicolumn{3}{|c|}{ Belgium } & \multicolumn{3}{|c|}{ France } & \multicolumn{3}{|c|}{ Netherlands } & \multicolumn{3}{|c|}{ Sweden } & \multicolumn{3}{|c|}{ Switzerland } & \multicolumn{3}{|c|}{ USA } \\
\hline $3 / 33 / 03 /-$ & 8 & 5 & 13 & 5 & 1 & 6 & 9 & 5 & 14 & - & - & 0 & 6 & 10 & 16 & - & 2 & 2 & 7 & 4 & 11 \\
\hline $3 / 4$ & 33 & 17 & 50 & 15 & 8 & 23 & 25 & 29 & 54 & 3 & 4 & 7 & 27 & 21 & 48 & 2 & 1 & 3 & 28 & 31 & 59 \\
\hline $4 / 44 /-4 / 0$ & 12 & 4 & 16 & 3 & 2 & 5 & 3 & 2 & 5 & 1 & 1 & 2 & 12 & 18 & 30 & - & - & 0 & 4 & 10 & 14 \\
\hline $4 /$ non $2,3,4$ & 9 & 14 & 23 & 9 & 12 & 21 & 17 & 16 & 33 & 2 & - & 2 & 17 & 12 & 29 & 3 & 4 & 7 & 18 & 30 & 48 \\
\hline $2 / 4$ & 1 & 2 & 3 & 1 & - & 1 & 3 & - & 3 & 1 & - & 1 & 1 & 1 & 2 & - & - & 0 & 1 & 5 & 6 \\
\hline Others & 5 & 6 & 11 & 3 & 2 & 5 & 7 & 5 & 12 & - & 1 & 1 & 1 & 1 & 2 & 3 & 1 & 4 & 9 & 8 & 17 \\
\hline Total & 79 & 55 & 134 & 47 & 35 & 82 & 87 & 80 & 167 & 9 & 9 & 18 & 68 & 64 & 132 & 8 & 8 & 16 & 93 & 103 & 196 \\
\hline
\end{tabular}

$\mathbf{M}=$ male,$\quad F=$ female

\section{Results}

The distribution of HLA-DR-types is shown in Table 3. HLA-DR 3 and/or HLA-DR 4 was found in $678 / 745$ (91\%) of the patients and DR 2 in only 47 patients $(6 \%)$, of whom 16 had HLA-DR 3 and 16 HLA-DR 4 . Of the 646 patients with HLA-DR 3 and/or 4 but without HLA-DR 2, girls were somewhat overrepresented among HLA-DR 4/non $3(125 / 235,53 \%)$ compared to DR $3 /$ non $4(72 / 167,43 \%)(p<0.05)$. This sex differ- ence was especially pronounced in the USA, although the same tendency was apparent among the European patients (Table 4).

Table 4 reveals some differences between the countries. In Sweden there were relatively few patients with DR 2 , or patients lacking both DR 3 and 4 compared to the other countries, but many patients with DR 4. In France there was a higher frequency of HLA-DR 3 and more cases lacking both DR 3 and 4 . 


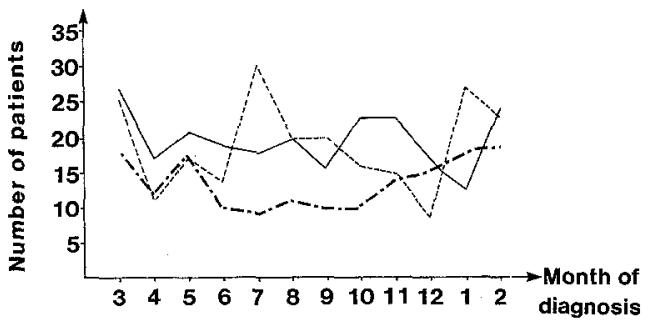

Fig. 3. Seasonal variation of diagnosis $(=1$ st insulin injection $)$ in relation to HLA-DR 3.....; DR 4 -..; DR 3/4 —; $n=625$

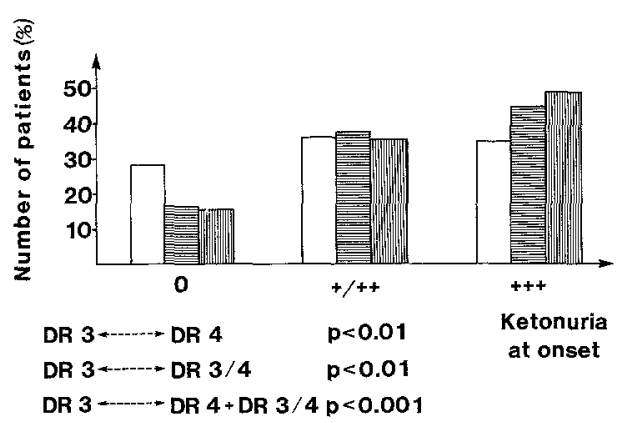

Fig.4. Rather often patients with HLA-DR 3 have no ketonuria at on-

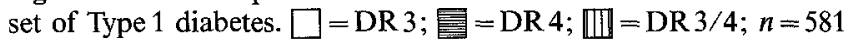

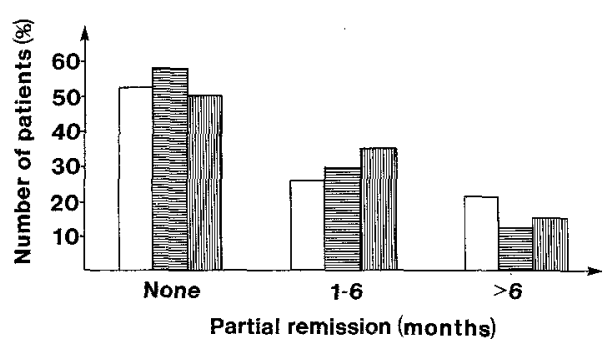

Fig.5. Patients with HLA DR 3 more often have a partial remission longer than 6 months compared to patients with HLA-DR 4 or

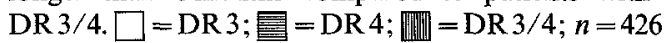

Age at diagnosis in relation to some HLA-DR-types is shown in Figure 2. Patients with DR 4 and DR 3/4 tended to develop manifest diabetes earlier with incidence peaks both around 7-8 years and 10-11 years, while the DR 3 patients lacked these incidence maxima and had rather stable incidence from 4 years up to 12 years, when incidence increased to a peak around 14 years. However, the difference is not significant for individual years. The seasonal variation is shown in Figure 3. Patients with DR 4 had wider seasonal variation than DR 3 patients, as DR 3 patients had no incidence peak during summer. Duration of symptoms before diagnosis was usually $1-3$ weeks, but varied from a few days to a year. A duration of less than 7 days was noticed in 132 patients, of whom only 4 were HLADR $3 / 3$ or $-(p<0.02)$.

At diagnosis $15 \%$ of the patients were said to have impaired consciousness (including $4 \%$ in coma). In this regard DR 3 patients again differed, showing impaired consciousness significantly less often than DR 4 or
DR $4 / 4$ patients $(p<0.05)$. This difference was even more marked when we compared ketonuria (Fig. 4, $p<0.01)$. High blood glucose at onset $(>20 \mathrm{mmol} / \mathrm{ml})$ tended to be found somewhat more often among patients with HLA-DR 3/4 or DR 4 than among those with DR $3(p<0.1)$. No information could be obtained from Pittsburgh regarding partial remission, but in the other centres partial remission was observed according to Figure 5 , which reveals only a tendency $(p<0.1)$ for DR 3 patients to more often have remission $>6$ months than the others. When comparing DR $3 / 3$ or DR $3 / 0$ with DR $4 / 4$ or DR $4 / 0$, as well as comparing DR $3 / 3$ or DR $3 / 0$ with DR $3 / 4$, this tendency becomes stronger $(p<0.01, p<0.01$ respectively).

The differences between HLA-DR3-patients and those with HLA-DR $3 / 4$ or 4 described above were found with varying significance, but always with the same tendencies within each country. We also obtained the same result if the four clinics with low numbers of patients were excluded. Except for the mentioned differences in age at diagnosis and frequency of HLADR 4, there was no significant sex difference.

\section{Discussion}

There are several methodological problems with this multicentre study, as different centres may have used slightly different definitions of the various clinical parameters and different laboratory methods. Such errors should blunt the results and make it even more difficult to find significant differences between the groups. It is, therefore, the more remarkable that we can confirm that there are indeed differences in the clinical presentation and course between patients with HLA-DR 3 and those with HLA-DR 4 or $3 / 4$ in this large, heterogeneous group [6,7]. The DR 3 patients more often have a slower onset, spread more evenly over the year, less often have severe symptoms and ketonuria, but more often have partial remission. These differences were seen within each sex. The same tendencies are seen in different parts of Europe and in the USA, even if there are some HLA differences such as the more homogeneous DR 3 and/or 4 diabetic population in Sweden than in the other studied countries. The sex differences, with more boys with onset at less than 5 years of age and more girls with DR 4 alone, do not explain the differences seen between the HLA-DR types. Above the age of 4 the HLADR types seem to be related to the incidence, as HLADR 4 patients have an extra peak in the summer as well as the peak in early spring which is seen in all groups. Furthermore, the second peak occurs later for DR 3/4 patients (autumn) and is lacking for DR 3 patients [7]. One could speculate on the possibility that DR 4 patients have a tendency to certain infections [4], which explains their extra peak, while DR 3 individuals tend to modulate the seasonal variation by its slower progress. The observation that all groups, including DR 3, have a 
peak in early spring, could reflect the influence of several factors like infections, inactivity, seasonal hormonal variation, etc. - factors which may influence rather than cause the manifest disease. HLA-DR 2 is rarely seen as expected $[8,9]$, but nonetheless there are some patients with DR 2 and with neither DR 3 nor DR 4 who get Type 1 diabetes. These patients do not differ in the variables we have analysed; they are, however, an interesting group which should be studied in more detail to determine if environmental factors could be involved in the etiology of their diabetes or if their DR 2 includes subtypes.

In conclusion, this study confirms that there are significant differences between those diabetic children who have HLA-DR 3 in comparison with those who have DR 4 or both DR 3/4. Thus, the phenotype expression of disease is modified by the genotype. Patients who possess an HLA-DR 3 antigen generally have a milder form of disease than patients without this marker.

Acknowledgment. This study was initiated after discussions at the meetings of the International Study Group on Diabetes in Children and Adolescents (ISGD). It was supported by Östergötlands Läns Landsting, the Swedish Diabetic Association, the Swedish Medical Research Council (grant B81-19X-078) and by Novo Research Institute, Copenhagen.

\section{References}

1. Fajans S (1981) Etiologic Aspects of Types of Diabetes. Diabetes Care 4: 69-75
2. Yoon JW, Austin M, Onodera T, Notkins AL (1979) Virus-induced diabetes mellitus. Isolation of a virus from the pancreas of a child with diabetic ketoacidosis. N Engl J Med 300: 1173-1179

3. Nerup J, Lernmark A (1981) Autoimmunity in insulin-dependent diabetes mellitus. Am J Med 70: 135-141

4. Bertrams J, Sodoman P, Gries FA, Schasse B, Jahnke K (1981) HLA-association of insulin dependent diabetes mellitus type 1. Dtsch Med Wochenschr 106: 927-932

5. Ludwig H, Schernthaner G, Mayr WR (1979) Ia-type alloantigens and humoral autoimmune responsiveness in insulin-dependent diabetes mellitus. Metabolism 28: 797-800

6. Ludvigsson J, Lindblom B (1984) HLA-DR-types in relation to early clinical manifestations in diabetic children. Pediatric Research 18: 1239- 1241

7. Weinberg CR, Dornan TL, Hansen JA, Raghu PK, Palmer JP (1984) HLA-related heterogenicity in seasonal patterns of diagnosis in Type I (insulin-dependent) diabetes. Diabetologia 26:199-202

8. Sachs JA, Cudworth AG, Jaraquemada D, Gorsuch AN, Festenstein $H$ (1980) Type I diabetes and the HLA-D locus. Diabetologia 18: $41-43$

9. Platz P, Jakobsen BK, Morling N, Ryder LP, Svejgaard A, Thomsen M, Christy M, Kromann H, Benn J, Nerup J, Green A, Hauge M (1981) HLA-D and DR antigens in genetic analysis of insulin dependent diabetes mellitus. Diabetologia 21: 108-115

Received: 22 August 1985

and in revised form: 17 February 1986

Dr. Johnny Ludvigsson

Department of Pediatrics

University Hospital

S-581 85 Linköping

Sweden 